\title{
Code Switching in the French School: Examining a Multilingual Setting in Kuwait
}

\author{
Nada A. Algharabali ${ }^{1}$, Fatma M. Alhaidari ${ }^{1} \&$ Hanan A. Taqi ${ }^{1}$ \\ ${ }^{1}$ The English Department, College of Basic Education, The Public Authority for Applied Education and \\ Training, Ardhiya, Kuwait \\ Correspondence: Hanan Taqi, The English Department The College of Basic Education, Ardhiya, Kuwait. \\ E-mail: hanan.taqi@gmail.com
}

Received: October 8, 2015 Accepted: October 26, 2015 Online Published: November 29, 2015

doi:10.5539/ells.v5n4p36 URL: http://dx.doi.org/10.5539/ells.v5n4p36

\begin{abstract}
Sociolinguistic studies on code switching have been of interest to educationists; especially when code switching occurs in schools among students. This study aims at analyzing the extensive amount of code switching between students studying in the French School of Kuwait, their preferences of code-switching, choice of language, and frequency of use of each language. The study is based on the data obtained from two questionnaires distributed to teachers and students; in addition to observation and note taking of conversations between students during home time - when the students were waiting to be picked up. It was found that, to students, code switching is a favorable social behavior, students mainly switch to Arabic and English, while French is considered the language of the school medium. The study also indicates that teachers and parents are agents that either encourage or discourage students' code switching.
\end{abstract}

Keywords: sociolinguistics, code switching, languages, school, language use, language preference

\section{Introduction}

By early adolescence, many middle school students in Kuwait have already learnt how to use linguistic resources as tools not only to simplify the process of communication with their peers and teachers, but also to negotiate language choices in a socially meaningful way, especially in multilingual and bilingual situations. Code switching is one of the commonly used linguistic resources by many students of different cultural and ethnic backgrounds. The French School of Kuwait or Lycee Française de Kuwait (LFK henceforth) is a typical case in point. Students, from all around the world (both of Arab origin, European, African, and other nationalities) are gathered in an institutional setting which employs the French language as the medium of education, while also introducing Arabic and English early on to $1^{\text {st }}$ and $2^{\text {nd }}$ graders subsequently, and eventually Spanish in senior school. With such a rich multicultural and multilingual background in mind, the presence of complex linguistic implications is inevitable, and manifests itself in the rapid alternation between languages, such as English, Arabic and French in many students' daily interaction with one another.

In fact, so routine and rapid are code switching and code mixing (Note 1) practices in LFK students' daily communication, that one would assume they were not even aware of such diverse linguistic behavior. These interactional practices, which usually occur between many students in school albeit outside the classroom, have captured the attention of the researchers of the present study and inspired the following sociolinguistic research queries: 1) Given that LFK students are taught French since kindergarten and should therefore feel very confortable speaking the French language, why then, are many students heard code switching mainly between Arabic and English while including French only when necessary? 2) How do LFK students perceive each language (Arabic, English and French)? And consequently, 3) is there a correspondence between how students perceive a certain language (whether positively or negatively) and how often they utilize that language in code switching?

\section{Code Switching: An Important Linguistic Resource}

To the fortune of many multilingual speakers, approaches to code switching have shifted in their understanding from being marginalized as a deficient linguistic behavior arising from a lack of competence in one or the other of the languages being utilized (Poplack, 1980, p. 615; Gumperz, 1982) to a privileged linguistic phenomenon 
that demonstrates skilled communication (Gumperz, 1982, p. 63). Although many schools, educators and teachers continue to perceive code switching as a negative trait that indicates sloppiness and laziness in students' speech (Hughes et al., 2006, pp. 7-8, Amorim, 2012, p. 179), anthropologists and sociolinguists mostly agree that it is an interactional strategy that is socially meaningful and accomplishes communicative functions and goals (e.g., Gumperz, 1982; Myers-Scotton, 1993; Rampton, 1995; Heller, 1999).

Gumperz refers to code switching between languages as 'the juxtaposition within the same speech exchange or passage of speech belonging to two different grammatical systems or subsystems' (1982, p. 59). Gumperz and Blom distinguish between 'situational code switching', which links the alternation between languages to a change of situation or social event, and 'metaphorical code switching', in which the alternation occurs in the same situation but presents a different view of the situation (Blom \& Gumperz, 1986, pp. 424-25). Gumperz later refers to both categories as 'conversational code switching' and suggests a taxonomy of different switches (such as quotations, reiteration, interjections, and so on) to identify the various functions of code switching in conversation (1982, pp. 75-81).

A more local and less macro approach towards code switching focuses on the participants themselves and how they wish their interaction to be interpreted in a particular context rather than assign social value to particular instances of code switching. Advocates of this approach view code switching from a conversational analysis perspective (CA) and therefore suggest that patterns of code switching both structure and are structured by the meaning that the speaker and hearer negotiate on a specific occasion (see Auer, 1989; Wei, 1989; Stroud, 1989). Poplack (1980) for example, suggests a more linguistic perspective toward code switching, which goes beyond certain situations or social significance. She suggests that code switching is mostly rule-governed and often does not occur randomly or violate morphological and syntactic rules of either language being used in one exchange (1980, p. 589). She (Poplack) defines code switching as switches that occur intersentential, in which speakers alternate between 'two languages within a single discourse, sentence, or constituent' (1980, p. 583).

A research path that has contributed fruitful insights into the functional understanding behind code switching is the one that relates to exploring the significance of code switching in schools and especially in classrooms (see for example, Eldridge, 1996; Lin, 2000; Gibson, 2003; Alenizi, 2010; Mahsain, 2015). In Kuwait, there is extensive research on the effects of code switching by teachers and/or students as a strategy or tool used in second language acquisition classrooms or in bilingual institutional settings (see for example, Alenizi, 2010; Mahsain, 2015). Very few studies however, examine conversational code switching through ethnographic observation, and specifically outside the school classroom. Also, hardly any research in Kuwait has looked at multilingual settings in schools that teach more than two or three languages, which justifies the strong rational behind the present study.

A final point worth putting forth on the practice of conversational code switching is the factor of participant intentionality, particularly among adolescent participants (Nilep, 2006, pp. 14-15). Some researchers have observed that code switching instances often signal intentional language choices by participants who wish to negotiate sociocultural features with regards to their identity, or establish in-group members and youth subcultures among adolescents or in some cases, exclude out-groups (Rampton, 1995, pp. 487-490; Jorgensen 2003, p. 128; Hughes et al., 2006, p. 8; De Fina, 2007). While the sociocultural context in which interlocutors engage in code switching may influence their language behaviors and choices (Rampton, 1995, p. 280), very frequently code switching is simply used as an unconscious strategy to facilitate the task of communication, especially when participants whose competence in the second or third language is still being developed are involved (Gumperz, 1982, p. 62; Milroy \& Muysken, 1995, p. 3; Elridge, 1996, p. 303). It is therefore often more helpful to examine the effect that conversational code switching has on the hearer and how it is interpreted based on shared cultural information between interlocutors, while also considering the social context within which this communication is taking place (Gumperz, 1982, pp. 63 \& 75; Auer, 1984).

Indeed, adolescents who commonly engage in code switching usually share more than the linguistic aspect of this practice, particularly when code switching is utilized among peers at school (Elridge, 1996). As mentioned above, shared popular socio-culture, such as a shared taste in music, movies, fashion trends and so on, means shared experiences and goals and therefore shared linguistic practices (Eckert \& McConnell-Ginet, 1992). This perspective has to be seen within other levels of meaning, such as cultural change, Modernism and Globalization - of which the Internet and social media are byproducts - that have influenced younger generations to write (text) and speak skillfully utilizing international languages, such as English, French and Spanish (to name a few). In part, this explains the prevalence of code switching strategies among teenage interlocutors (Milroy \& Muysken, 1995; Gardner-Chloros \& Finnis, 2003). 
One of the more tangible manifestations of code switching is the omnipresence of universal (albeit English in origin), burrowed expressions used in teenagers' speech nowadays. Such expressions, for example $O M G$ (Note 2), Sup (Note 3), LOL (Note 4), and so on - were originally used as part of social media lingo and have somehow shifted into teenagers' daily verbal communication from both English and non-English speaking backgrounds. The consensus among a large part of the teen culture seems to indicate that teenagers who are unaware of such 'hip' expressions are seen as not belonging to the 'social media generation' (Rosenthal \& McKeown, 2011, p. 763).

In summary then, the examination of code switching as a strategy or a tool among teenagers warrants attention to be given to the investigation of both the sociocultural purpose behind utilizing this linguistic behavior and to the speaker's intended or unintended meaning as well as the hearer's interpretations of code switching instances. Consequently, the aim of the present research is to explore the linguistic and sociocultural significance of code switching between Arabic, English and French among teenage students in the multicultural and multilingual setting of LFK.

\section{LFK Students' Linguistic Background}

Established in 1989, LFK is the only French school in Kuwait and therefore the only educational setting where French, English and Arabic are used together in the students' daily interaction, quite often outside the classroom. Based upon the observations of one of the researchers in the present study (Note 5), it has been noted that students at LFK frequently switch into Arabic and English and to a lesser extent into French during the home time period while waiting to be picked up by their parents at the school's outdoors waiting area. Interestingly, the Arabic dialects being spoken by many of the Arab students are colloquial dialects that link each student to his/her different country. Consequently, a mixture of dialects: Syrian, Lebanese, Moroccan, Egyptian, Kuwaiti and others, are all mostly, mutually intelligible and are all overheard coming out of groups of children and teenagers who are excited to go home and therefore too busy to notice the rich linguistic mixture of Arabic dialects audible in such a confined area, $10 \times 10$ meters.

Of course, Arabic is sometimes avoided or translated into other languages (English or French) for the benefit of French or Francophone students who do not speak the language. But often, the mixture of Arabic dialects is also mixed with English and/or French by students who just want to get the message across. The percentage of usage of English and French varies based on the participants' competence of these two languages. This diverse sociolinguistic setting has raised the interest of the researchers involved in this study who were curious about the rapid and frequent instances of code switching and mixing practices that took place between LFK students. This study therefore explores students' and teachers' perceptions toward the practice of code switching into Arabic, English and French in students' daily interactions outside the classroom. The limited scope and range of this mainly quantitative study is not to examine the students' attitudes towards the French language alone in order to establish why many students were code switching mainly between Arabic and English. In fact, given that French is the school's mainstream language, it would be quite natural for LFK students to communicate in French even during casual chitchat outside the classroom, but that did not seem to be the case in many instances. The aim of the present study then, is to provide teachers and educators at LFK with an awareness as to how often students tended to code switch between Arabic, English and French and why did they engage in this linguistic behavior.

\section{Methodology}

The present study initially began with the purpose of finding out on a large scale how often were LFK students' code switching into Arabic, English and French during daily interactions with each other? And, why were they engaging in this linguistic behavior? To do so, a large-scale quantitative examination would be carried out to demonstrate students' and teachers' perceptions towards code switching and how much of this practice was part of the students' daily repertoire. The quantitative data would then be triangulated with sociolinguistic-type interviews and ethnographic observations to record natural occurring speech, and thus introduce data that can be analyzed qualitatively in order to show various patterns of code switching and their different functions.

Unfortunately, when introduced to LFK by the researchers, this plan was met with strong reservations from the school's administration and only limited access was granted. The administration's rational behind allowing us limited access was that among the students attending LFK, were sons and daughters of diplomats and ambassadors. This entailed that no video, audio recording or note taking was allowed inside the school. In fact, the school's administration set limits to any data that was collected even outside the school in the home time waiting area where the researchers had planned to conduct ethnographic observation during the short time (from 10-15 minutes) in which students were waiting to be picked up by their parents.

Alas, the methods of the present study are limited to a students' questionnaire (see Appendix A) that pivots 
around the research questions mentioned earlier. A hundred copies of the questionnaire were distributed to students whose age ranged from 12 to 18 years. In addition to that, a teacher's questionnaire (see Appendix B) was presented to LFK teachers, a number of whom refrained from taking part in the present research. Both questionnaires were translated into French for the benefit of the participants and they both had one open-ended question toward the end, which asked participants to comment by sharing their perceptions on code switching between Arabic, English and French. The idea behind this final question was to gather as much insight from both teachers and students pertaining this linguistic practice, which seemed to occur very frequently in many students' exchanges.

The researchers were also allowed access to the school's home time waiting area that is located outside the school door, but technically still part of the school parameters. The student observation process was carried out during a period of 10 days and for 10 minutes each day. Longer than that length of time would have been physically intolerable due to the intense hot weather conditions $\left(45^{\circ} \mathrm{C}\right.$ in the shade). Also noteworthy here, is that the researchers were only allowed to take field notes and observe code switching patterns found in students' speech, since they were denied access to any video or audio recording.

Due to these numerous limitations set by the school administration, one of the researchers (Algharabali) had to find other options to gather data. There were numerous occasions, in which friends (male and female students) from LFK were invited for lunch and 'hanging out' with the researcher's sons at her residence. After requesting consent from the parents of the student invitees, the researcher was able to include in her field notes some of their interactional dialogues, comments and insights to questions asked about the practice of code switching. Of course, prior to that, the researcher had to ensure that the school was not opposed to this method of data collection. It is worth mentioning that these types of lunch invitations were a common occurrence at the researcher's residence especially on the last day of a school week.

\section{The Results}

\subsection{The Questionnaire}

\subsubsection{Teachers' Questionnaire}

The study involved 15 teachers who participated by filling in the questionnaire and commenting on the issue of code switching. Most teachers $(73.3 \%)$ believe that students start code switching at about 5 years of age. However, testing the significance of gender with the age of the students' code switching in a one-way ANOVA by gender, significance was found at $\mathrm{p}=0.007$ (where significance is calculated at $\mathrm{p}=0.05$ ). The results indicate that male teachers sense that students start code switching more tangibly at ages $14-16(\mathrm{~m}=1.20$ of an average $\mathrm{m}=1.00)$.

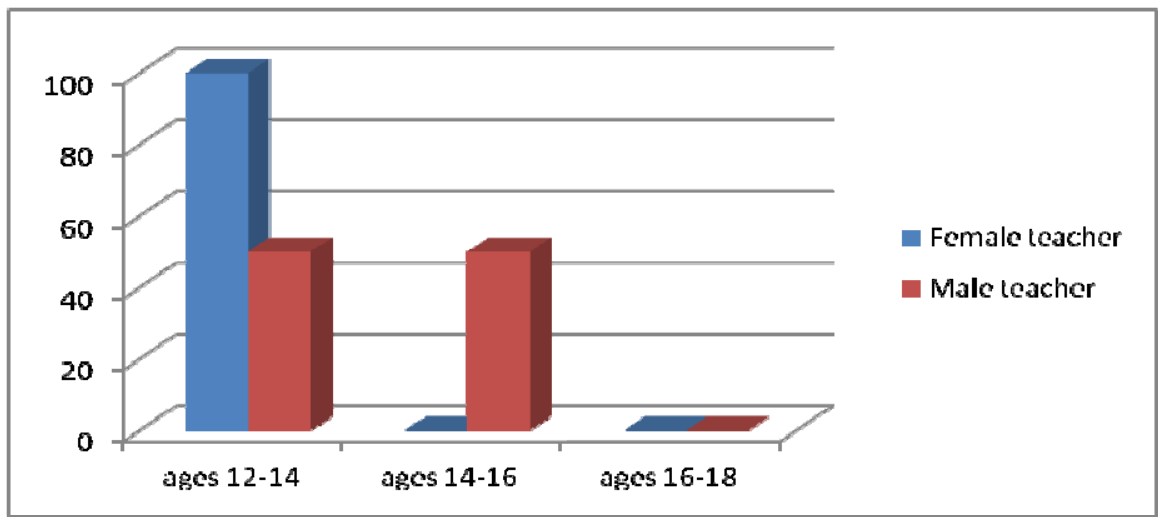

Figure 1. Male teachers vs. Female teachers and age of code switching

As seen in Figure 1, half the male teachers stated that code switching comes at a later age.

When teachers were asked which gender code switches most, the far majority of teachers reflected their belief that both genders equally code switch (66.7\%). The reasons for code switching differed; however, $36 \%$ of the teacher participants stated that the lack of vocabulary in a certain language is the main reason behind code switching. On the other hand, $28 \%$ of the teachers felt that code switching was due to peer pressure, and $20 \%$ thought it was comfortable for students to code switch. 
The majority of the teachers participating in this study (86.7\%) prefer that their students would utilize French in class. In addition, $60 \%$ of the teachers would like their students to utilize French during recess. Nevertheless, when the teachers were asked how often they would like students to utilize French at home, the results differed. Only $13.3 \%$ of the teachers felt that their students should speak French at home, as opposed to $53.3 \%$ who felt that the students rarely needed to speak French at home. Finally, the teachers where asked how often they thought students code switch? It appears from the statistics obtained that $46.7 \%$ of teacher participants believe that the students code switch often, and $40 \%$ believe that they rarely code switch (refer to Figure 2 below).

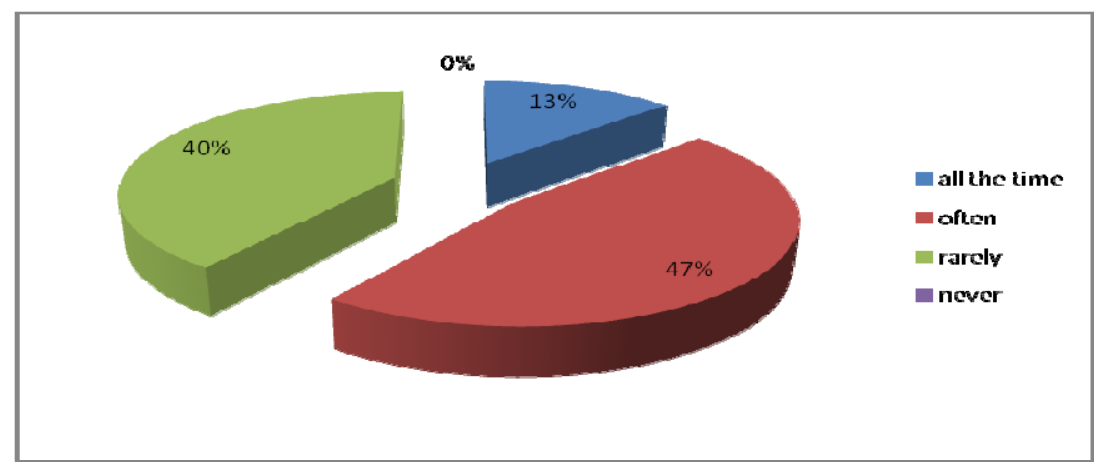

Figure 2. How often do students code switch

From Figure 2, it is clear that the teachers do not see code switching as a threat.

\subsubsection{Students' Questionnaire}

The students' questionnaire consisted of three independent variables (age, gender and nationality); in addition to 11 dependent statements, three of which allow students to choose several answers. 95 students participated in filling in the questionnaire, 38 male and 57 female. About half the participating students left a comment at the end of the questionnaire as part of the final open question (see 4.0, above)

From the analysis of the data obtained from the students' questionnaire, it is clear that the majority of students code switch, even the students whose mother tongue is French (as appears from their nationality). While $45.3 \%$ of the students stated that they always code switch at recess, $23.2 \%$ stated that they sometimes code switch, while $15.8 \%$ never code switch. A two-way ANOVA by gender, by age and by the amount of code switching with friends showed significance of $\mathrm{p}=0.02$, as the youngest group of male students seemed to code switch the most. Nonetheless, the students who code switch at school do not always code switch at home. More precisely, $23.2 \%$ of the students never code switch at home, and never code switch with their parents. A higher percentage (27.4\%) was found not to code switch with siblings either. Hence, the results show that code switching in school, and with friends, occurs more often. While $34.7 \%$ of the participating students stated they always code switch with their parents, $45.3 \%$ always code switch when they are with their friends. Moreover, only $29.5 \%$ of the students always code switch with their siblings (bearing in mind that $6.6 \%$ of the students are single children).

The question that imposes itself at this point is: why do students code switch? Students were offered five reasons, and had the choice of selecting any of the five as seen suitable (see Appendix A). The statistics show that 'comfort' is the most common reason for code switching during recess time, home time and for general communication with an average percentage of $48.3 \%$. It is noteworthy here that comfort might appear to be a general term involving many other reasons. Another influential reason was investigated, and 'peer pressure' was found to be the second most important reason for code switching with an average of $18.5 \%$, followed by 'exchanging secrets' (12.5\%) and 'lack of vocabulary' (11\%). The least important reason was 'laziness' with an average of $9.6 \%$.

Comfort was the number one reason for code switching at recess, home time and during general communication $(42.1 \%, 46.2 \%$ and $56.7 \%$ successively). $19.2 \%$ of the students code switch as a result of peer pressure at recess, $23.9 \%$ at home, and $10.5 \%$ during everyday communication. Laziness was found to be the least common reason for code switching at recess and at home; however, it is the second most common reason for code switching during general communication (14.4\%). Figure 3 below reflects the percentages of the common reasons for code switching. 


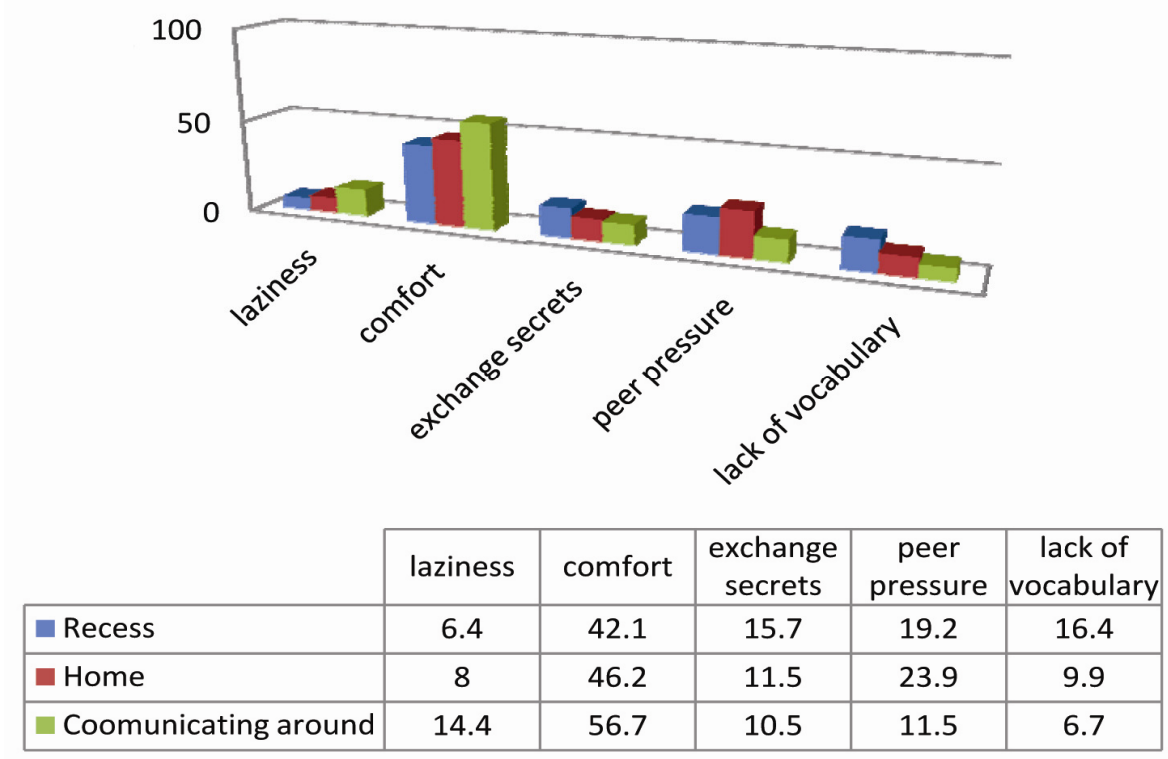

Figure 3. Percentages of reasons for code switching

As seen in Figure 3, "comfort" is the most common reason for code switching.

It appears from the statistics that the participating students believe that the teachers do not encourage code switching in school. $45 \%$ of the students stated that they feel that the teachers would like them to speak in French more often, and $20 \%$ thought that the teachers do not prefer them to mix between languages at school. This comes hand in hand with the teachers' statements in the final commentary section of the teachers' questionnaire, which reveals that $73.3 \%$ of the teachers preferred students to utilize French in school and minimize code switching practices (see 5.1.1, above).

The majority of students (68.4\%) noted that their parents were not bothered with their code switching; yet $20 \%$ stated that their parents mind to a certain extent. A further analysis of this statement shows high significance when a one-way ANOVA by age was calculated, it was found that $p=0.006$ as the eldest age group felt that their parents minded to a certain extent significantly more than the other two age groups. Figure 4 below, reflects the distribution of age with the statement reflecting the parents' attitude towards code switching practices from the students' view point.

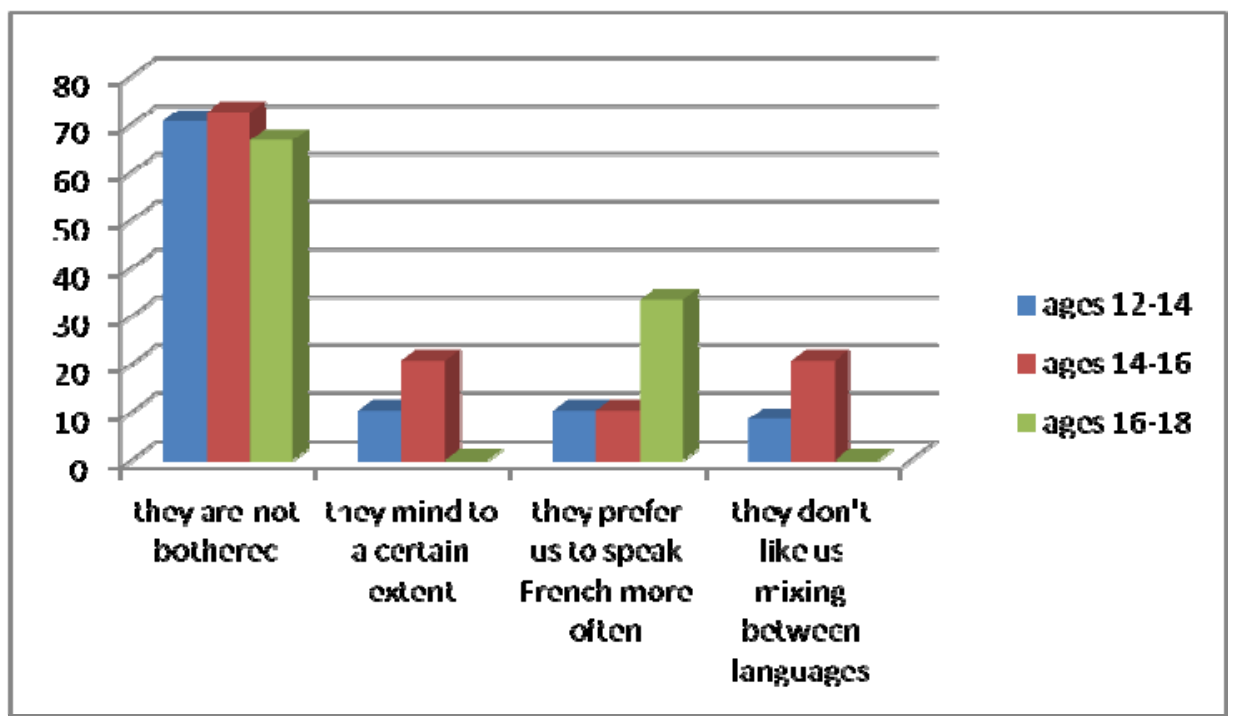

Figure 4. Age group and parents' perspective towards code switching 
As reflected in Figure 4, the third age group, more than others, reflected their belief that their parents do mind their code switching practices to a certain extent.

The final question asked the students how often they believe they code switch. Most students participating in the study believed that they often engage in code switching (40\%), while $27.4 \%$ stated that they always code switch. $23.2 \%$ of the participants believed that they rarely code switch, the majority of which, as it appears from their nationality, seemingly come from French speaking backgrounds.

\subsection{Some Qualitative Evidence}

While the study's questionnaires mainly sought to collect quantitative data from LFK teachers and students, the researchers have also drawn on qualitative evidence by asking all participants an open-ended question at the end of both questionnaires (see Appendix A and B). To elicit insights and discussion on the way teachers perceive code switching, the researchers asked the following: "Please do not hesitate to comment on the idea of students mixing between $(\mathrm{Fr} / \mathrm{Eng} / \mathrm{Arb})$ when communicating." From a sociolinguistic perspective, the researchers provided this kind of question in order to understand the complex linguistic situation of how often LFK students code switch in class and at home while realizing the aim of this study which is presenting LFK teachers with a clearer picture of when do students code switch and for what reasons (see 5.2.2, below).

It was hoped that the comments offered by both teachers and students would complement the ethnographic observations which took place while students were being picked up by their parents at school during the home time period, as well as during informal lunch gatherings involving a few students from LFK (see 4.0, above). All of which would add authentic insights to the present study. Similarly, students were also encouraged to provide comments about their code switching practices following the same method that was utilized to elicit feedback from teachers (see 5.2.1, below).

\subsubsection{Teachers' Comments}

Out of the 15 teachers ( 4 males and 11 females) who participated in filling the questionnaire, only one male teacher commented on the issue of code switching by saying: "Speaking other languages helps students to develop/progress, especially since they have to use only French for most subjects." Although this comment is insufficient to prove that LFK teachers perceive code switching as a positive or negative language tool, it in fact suggests that at least one male teacher believes that his students are developing their identities and progressing intellectually through speaking other languages besides French (see Gumperz, 1982; Myers-Scotton, 1993; Rampton, 1995; Hughes et al., 2006; De Fina, 2007).

To the contrary, the female teachers' comments have made a significant contribution to understanding how LFK teachers perceive students code switching into Arabic, English and French. Eleven female teachers agreed to do the questionnaire, but only 6 participants answered the open-ended question (see Appendix B). Interestingly, each teacher commented differently, offering six insightful accounts of the use and the reasons leading students to engage in code switching. For instance, one French teacher described mixing as a normal habit, which students tend to pick up from their parents. Likewise, another Lebanese teacher wrote: "Even adults mix between languages, especially the Lebanese," highlighting her ethnic background as a rich multilingual community for code switching. Similarly, ethnicity is also illustrated in another account of an Algerian female teacher, "The ethnic background of the student influences mixing between languages." Therefore, ethnicity could very well be one factor perceived by LFK teachers as an influential motive to code switching, thus substantiating Jegede's claim, which suggests that most primary school, multilingual Nigerian students in his study expressed themselves in classroom using two or three languages, mostly including the use of their ethnic languages (2012, p. 45).

An insightful account offered by yet another Lebanese teacher regarding the effect of technology and communication tools on students' languages emphasized that: "Technology such as (WhatsApp, Google, video games and TV) have a strong influence on the students' mixing of languages." This view strongly relates to the idea suggesting that different hip teen expressions commonly utilized nowadays by teenage interlocutors, such as ' $L O L$ ' and 'sup' to produce shortened language expressions in order to fit into the globalized culture of Internet and technology (Rosenthal \& McKeown, 2011; Hall, 1996, discussed in 2.0, above).

The last two comments were more intriguing with regards to recognizing how LFK teachers perceive French as the first language of the school which should be utilized for everyday communication as well as their own interpretation of language acquisition. "We encourage students to read and watch TV programs all in French, during summer vacation so that they remain in touch with the language," one French teacher wrote. This teacher emphasizes the key position of the French language and points out the necessity for LFK students to utilize 
French during the summer holiday in order to maintain their level of language acquisition.

And finally, another teacher who is French of Lebanese descent, states that "The students never acquire one language $100 \%$ and this is very unfortunate." This poignant comment demonstrates her belief that students do not reach full competency in one language. This also seems to imply that engaging in code switching behavior provides the students with a middle ground area, akin to a comfort zone that does not necessitate developing one necessary language, in this case the French language since it is the school's medium of instruction. The teacher also appears to suggest the language situation of engaging in code mixing practices (which ultimately means the lack of proficiency in any one language) is an unfortunate state of affairs (see Poplack, 1980; Hughes et al., 2006; Amorim, 2012).

\subsubsection{Students' Comments}

When observing the previous comments of LFK male and female teachers, it is evident that most of them prefer French to be the sole language of teaching and everyday communication, but do not seem to recognize code switching as a real threat to the students' language proficiency. However, given that only few of them agreed to express their thoughts in the questionnaire, it is probably difficult to claim a solid comprehensive understanding of the way they perceive code switching. In this case then, it is necessary to examine the students' feedback from the questionnaire, as this will provide us with a better understanding of how they (the students) perceive the practice of code switching as well as their perceptions on what their teachers think of students engaging in code switching. Unlike their teachers, the majority of students freely expressed their beliefs on code switching, revealing substantial accounts of this paper's pivotal query which is: Why do French students in Kuwait code switch into English, Arabic, and French?

Age and gender were significant independent variables in the students' questionnaire but not for teachers. Out of the 95 students (57 males and 38 females) who participated in filling the questionnaire, 13 male and 28 female students described their views and reactions toward code switching inside and outside school. Although younger male students ranging from 12 to 14 were the ones to code switch the most among all male and female age groups, only 10 from that age group shared comments with regards to code switching. In both gender groups, students ranked 'comfort' as the most common reason for code switching, followed by 'peer pressure', 'exchanging secrets', 'lack of vocabulary' and lastly 'laziness'.

Those 10 male students have reported different opinions regarding code switching; 5 accounts were positive while the other 5 were negative. A few students associate the important value of English as an international language nowadays to the reason why students engage in code switching. A reflection of the practical significance of English is sensed from a comment passed by one of the students: "The best language ever is English". According to some students a "lack of vocabulary" in the French language is perceived as another reason for code switching (Poplack, 1980; Hughes et al., 2006; Alder, 1998). Other students felt that if anything, code switching enriches students' vocabulary in other languages, such Arabic and English. However, the students are well aware that this is not how their teachers view code switching, in fact, according to the statistical data, the majority of male and female students claim that their teachers discourage code switching in class. This is clearly expressed in one of the students' comments on the questionnaire: "Students are not allowed to speak other than French in class" (see Jegede, 2012). Other students expressed the idea of the teachers' lack of tolerance to languages other than French being used in class by saying, "I wish our teachers would allow us to speak the way we like and use whichever language we want. This is so unfair." This last comment was expressed by a half Spanish half Indian student who seems to be longing to speak all three languages: English, French, and Spanish.

Besides a lack in vocabulary, another reason to code switch is a general laziness while communicating, that is to say using the first word that comes up in whatever language is available in the speaker's repertoire, usually without upsetting the structural flow of phrases or sentences (see Poplack, 1980). This is according to one of the students who states when commenting on code switching being a positive practice: "Mixing between languages is very useful at times, especially when we're too lazy." Sometimes, the comments the students provided seemed to reflect their attitude towards a specific language. For example, considering that the Arabic language is associated with many of LFK students' identities or backgrounds, a few students aired their perceptions towards it. One student projected a negative attitude towards Arabic by stating, "I don't like speaking Arabic when I am speaking foreign languages (Note 6)." The student makes it explicit that Arabic is not one of his favorite languages despite being American from Libyan descent. However, not all students have a limiting regard towards Arabic, in fact, many students consider the geographical location of their school to be the main reason that leads them to code switch frequently, this is clear from their comments: "Kuwait is an Arab country where 
we have to speak Arabic" and "It's difficult not to mix between languages in an Arab society where everyone speaks a different language or dialect." This also implies that the factor of peer pressure seems to encourage others to engage in code switching practices, as one student mentioned: "Students copy one another. When one speaks in English the other answers him/her in English so its peer pressure, really" (see Liang, 2006).

The final comment in this group describes the impact of the other interlocutors and the context of interaction. One of the students expressed this idea by stating that, "We engage in code switching depending on the people present during an exchange as on the place we're in at the time." For bilingual or multilingual speakers, the actual speech setting where code switching takes place, the speakers involved, and the relationships between speakers are vital factors to situational code switching (Gumperz, 1982; Gumperz \& Bloom, 1986; Wei, 2007).

In the case of the second group, older students aged 14 to 16 , very few students commented on the practice of code switching and their comments were no different than those discussed above by the students whose age range is 12 to 14 years old. That is except for one notable comment with regard to the intentionality of code switching between French, English and Arabic. One of the students in this age group pointed out to the unintentional nature of this practice, stating that it is "a habit and not done on purpose" (see Gumperz, 1982; Milroy \& Muysken, 1995; Elridge, 1996, discussed in 2.0, above).

\section{Discussions}

Through the findings from the questionnaire based on both quantitative and qualitative data, it is evident that LFK teachers and students perceive code switching in a different way. Teachers who agreed to take part in the questionnaire believe that French is by default the language of the school and therefore should be utilized in daily communication. To the contrary, many students indicate a strong preference to engage in code switching between Arabic, English and French. First and foremost, the results clarified above helped the researchers to answer the three research questions proposed for this study, adding further sociolinguistic feedback and explanations, particularly from Algharabali's informal interviews with a few students and ethnographic observations in Algharabali's residence and observational perceptions elicited from the school's home time waiting area.

Based on the questionnaire data and the comments offered by students and teachers, it has been observed that LFK male and female students code switch between Arabic and English with a slightly narrower use of French to achieve various social and linguistic goals (Gumperz, 1982; Myers-Scotton, 1993). Among the male students, code switching is practiced for the following purposes: 1) develop the language (Arabic, English and French), 2) improve their vocabulary by learning new words in all languages, 3) switching into Arabic or English due to lack of vocabulary in French, and 4) when being too lazy to focus on one language (Hughes et al., 2006). Furthermore, they pinpoint three essential factors that motivate them to code switch, the geographical location or context where code switching occurs, the people engaged in the interaction (i.e., their ethnic backgrounds and whether they speak and understand only French or are multilingual, such as the case of many LFK students), the simplicity of the other language (that is either Arabic or English, or both) and the social distance between the interlocutors (that is, whether they are close friends or simply classmates) .

Predictably, it was found during the casual chats between students within school premises at the home time waiting area and at Algharabali's home that the vast majority of male and female students were indeed mostly code switching between Arabic and English with limited use of French. During two weeks, Algharabali observed code switching behavior among students in both sites, noticing random spontaneous code switching practices across all age groups. At school, Algharabali's ethnographic observational data showed that several students of varying age groups code switched between Arabic, English and, less often, into French. Many students' exchanges were peppered with fillers (e.g., 'like') and interjections (e.g., 'Oh my God!' and 'yeah right!') in English, tags (e.g., 'right': 'صح' sah (right?) and يعني yaSni (meaning) in Arabic). French seems to be mainly reserved for borrowed words that students have been hearing and using since kindergarten (e.g., 'CP' and 'CM1' meaning first and second grade, respectively, and 'colle' meaning: when a student is given detention) or words that students could not find the equivalence for in Arabic or English (e.g., 'degage' meaning get out of here, 'mais q'es tu fou' short for 'mais q'est ce que tu fou' meaning what ridiculous thing are you doing and 'bille' meaning marbles).

When recounting past events, telling stories or explaining an idea many students tended to favor switching between Arabic and English, while including French only minimally. In fact, Algharabali noticed that the use of the French language was often limited to exchanges that took place in the presence of participants whose competence of Arabic and/or English is poor. She also observed that her own sons and their friends spoke Arabic (each used his/her own dialect, which once again raises the idea of the identity and ethnicity of these Arabic 
speakers) and English (especially utilizing 'hip' English expressions, such as: 'epic fail', 'you gotta be kidding me' and 'no way', which are widely used among teenagers). In one of the dialogues that took place between 3 girls and 3 boys, whose age ranges from 12 to 13 years old, Arabic and English were the two main languages being used in addition to occasional French expressions. The exchange in Extract 1 (below), which took place at Algharabali's residence, begins by most participants talking about a mutual friend at school. They are having pizza for lunch (one of the female participants was quiet most of the time). Letter pseudonyms were used to protect the identity of students (For transcription, see Appendix C):

\section{Extract 1}

1 A: (male) Khilsou il five minutes? (Have the 5 min finished?)

2 B: (female) Yup.

3 C: (male) Shu loon Sha Sroo? (What color was his hair?)

4 A: (male) Sha froo taweel (his hair was long) kaan (it was) brown $A w$ (or)

5 black.

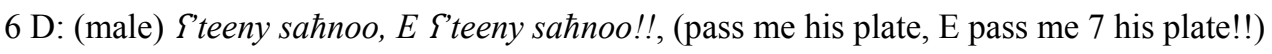

8 B: (female) Mais attend!! (wait!!) [She pauses and then passes him the plate,

9 eventually.]

10 D: (male) Thank you!

11 [points at the two types of pizzas and asks A.] Which one do you want

12 Margarita wala (or) Pepperoni?

13 A: (male) [doesn't answer]

14 D: (male) yalla! (come on!) which one?

15 A: (male) Pepperoni

$16 \mathrm{~F}$ : (female) [back to topic about their friend] Anyway, what about him?

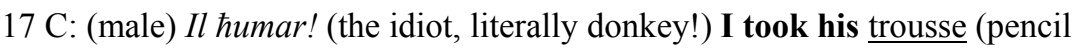

18 case) and never gave it back to him.

19 B: (female) [shows shock] Oh my God!

20 C: (male) ћabeebi! (My dear!) he's my best friend. You better give it

21 back to him!

22 B: (female) Sah! (Yeah!)

23 D: (male) Don't' worry, I will.

This relaxed conversation between familiar friends shows that multilingual speakers attending the same school tend to favor Arabic and English in their friendly chitchat, especially when they (the participants in this exchange) are Arabic speakers. Many of the examples from the exchange above uncover significant features in regard to why LFK students code switch between Arabic and English despite being competent speakers of French. One is that code switching operates as a social interactional behavior serving various goals for the group members (Gumperz, 1982; Myers-Scotton, 1993; Rampton, 1995). This group of friends gathered informally out of school premises to talk openly and discuss shared knowledge; thus, creating a unique youth subculture for the group (Jorgensen, 2003). The topic of discussion can be another feature leading students to use Arabic and English during this exchange in which students described a friend they all know how one member of the group stole his pencil case. Fishman argues that sometimes the topic of the conversation acts as a regulator tool when multilingual speakers choose one code over the other. He explains that, "certain topics are somewhat handled better or more appropriately in one language than another" (1986, p. 439). When talking about the pencil case

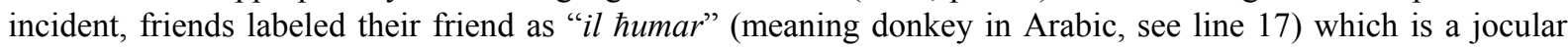
expression of abuse that not only signals the close relationship to that friend, but also establishes a strong bond between members of this group of friends, while bearing in mind that this kind of Arabic expression is commonly used between teenagers in Kuwait. One more Arabic word that discloses membership is " $\hbar a b i b i$," (my dear, see line 20) used at the beginning of an English sentence. Also a very common expression used among friends and loved ones to signal closeness. Intrasentential code switching is a common feature in this exchange, 
too (Auer, 2002; Myers-Scotton, 1993). This occurs either by inserting Arabic or English at the beginning, middle, or end of the sentence, as in "khilsou il five minutes?" (are the five minutes over?, see line 1).

Arabic and English were also used in common idioms such as "yalla" (come on) and "Oh my God!" Another interesting feature was the use of English to label colors, as in "brown" and "black." (see lines 4 and 5). Students also used the Arabic preposition of " $a w$ " (or, see line 4) to connect English lexical items or phrases, once again utilizing intrasentential code switching instances (Myers-Scotton, 1993). In terms of the few French words that were used, evidently, students chose words they acquired at school, at a younger age. For example, when retelling the event of stealing, the word pencil case was uttered in French (trousse, meaning pencil case, see line 17). Additionally, one female student used French to express her anger during the plate passing. She showed her disapproval by saying: Mais attend!! (wait!!, see line 8), which while demonstrates impatience, also seems to signal closeness between friends as opposed to social distance and the use of a more polite expression (Holmes, 2013; Al-Khatib, 2003). It is clear from Extract 1, that students preferred to code switch between Arabic, English and very minimally into French showing that this mode of speech is a common linguistic practice between group members, in which they are able to demonstrate their shared multilingual background, especially when utilizing a mixture of Arabic, English and French to recount shared experiences and familiar situations and people.

Interestingly, after listening to the above exchange between this group of friends and other examples of exchanges like it, Algharabali asked the participants (some of whom were Lebanese and others Syrian) why they tended to switch mostly between English and Arabic rather than say, French and Arabic or simply communicate in French alone, especially since they attend a French school? The simple answer was: "Arabic is our language, English is easy, popular and so cool, and French is nerdy and belongs in the classroom. And so, it's much more comfortable for us just to speak Arabic and English". Figure 5 below, captures the general outlook of LFK students towards the three languages (English, Arabic and French) and their perceptions towards the usage of these languages in casual, daily interaction with their school friends. This outlook is drawn from the quantitative and qualitative data in the present study.

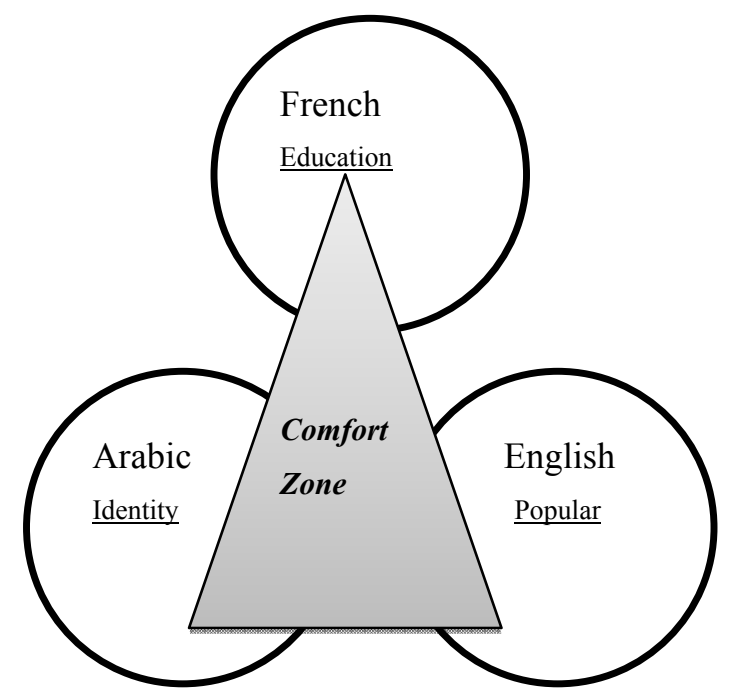

Figure 5. A representation of how LFK students perceive their pattern of communication with their friends outside the classroom at LFK

\section{Conclusion}

This study has attempted to examine why multilingual students of LFK code switch between English, Arabic, and French and the various sociolinguistic functions that motivate them to engage in this linguistic practice during their daily interaction. The aim of this study was to understand the rich linguistic behavior of code switching among one youth group in Kuwait, namely LFK students. The researchers also sought to answer three sociolinguistic inquiries regarding their preference to code switch between English and Arabic, their perception of English, Arabic, and French, and investigate whether the student's attitudes of each language are connected to the frequent usage - or lack thereof - of a particular language while code switching. In general, the overall results of this study correlate to previous literature on code switching as a valuable linguistic practice to most 
bilingual and multilingual speakers (Gumperz, 1982; Myers-Scotton, 1993; Rampton, 1995; Heller, 1999; Hughes et al., 2006; De Fina, 2007; Jorgensen, 2003; Milroy \& Muysken, 1995; Gardner-Chloros \& Finnis, 2003).

In this study, the findings presented seem to suggest that code switching is in fact a desirable social behavior by most LFK teenagers (Jorgensen, 2003). In most of the comments and ethnographic data, male and female students perceive English and Arabic to be their preferred languages for code switching. English is perceived, as the cool popular language while switching into Arabic is comfortable because it is the language that units many Arabs in Kuwait. On the other hand, many students view French as the language of the classroom while also believing that it is quite beneficial, especially when speakers lack certain vocabulary in Arabic and English as well as when interacting with monolingual students who speak only French. It was also found that LFK students code switch for different reasons such as comfort (Holmes, 2013), peer pressure (Liang, 2006), in private conversations to show solidarity and affection (Holmes, 2013; Al-Khatib, 2003), lack of vocabulary (Poplack, 1980), and laziness (Amorim, 2012).

Investigating code switching in this study also shows that parents and teachers are two important agents leading students to choose one language rather than the other. Sometimes students chose English or Arabic due to their parents wish, mainly to speak it at home and when teaching a sibling. To the contrary, French is used at school for its authoritative status and its status as the classroom medium of instruction. The findings from the commentaries shed light on how teachers require students to use French only, especially in classroom. Several students expressed not giving them the choice to select their preferred language of classroom, exemplified in Alenizi (2010) and Jegede (2012). Thus, it can be concluded that most LFK students code switch between English and Arabic naturally, either at home or in recess with friends and add French when necessary.

This study not only presents the idea of why students in a multilingual setting engage in code switching practices but also why they sometimes choose to avoid using a language they have been taught at school (from kindergarten until high school). Undoubtedly, the results reached in this study cannot be generalized or said to be representative of the whole of the LFK multilingual population. This is mainly due to the limitations imposed on the researchers by the school administration. Nevertheless, the results suggest that further research is needed in uncovering the conscious and/or unconscious effects of English as an international language in multilingual settings, especially in Arabic-speaking communities. Additionally, necessary research with regards to the position of the French language in multilingual contexts among Arabic speakers of non-francophone countries will add valuable insight in fields, such as multilingualism and language variation.

\section{References}

Alenezi, A. (2010). Students' language attitude towards using code-switching as a medium of instruction in the college of health sciences: An exploratory study. ARECLS, 7, 1-22.

Al-Khatib, H. (2003). Language alteration among Arabic and English youth bilinguals: Reflecting or constructing social realities? International Journal of Bilingual Education and Bilingualism, 6, 409-422. http://dx.doi.org/10.1080/13670050308667794

Amorim, R. (2012). Code Switching in Students-Student Interaction: Functions and Reasons! Revista de Estudos Linguisticos da Univerdade do Porto, 7, 177-195.

Auer, P. (1984). Bilingual Conversation. Amsterdame: John Benjamins. http://dx.doi.org/10.1075/pb.v.8

Auer, P. (1998). Code-switching in conversation: Language, interaction and identity (pp. 1-24). Routledge: London.

Baider, F. (2013). Cultural Stereotypes and Linguistics Clichés: Their usefulness in intercultural competency, Interactional Journal for Cross-Disciplinary Subjects in Education, 4(2).

Blom, J.-P., \& John, G. (1986). Social Meaning in Linguistics Structure: Code-switching in Norway. In J. Gumperz \& D. Hymes (Eds.), Directions in sociolinguistics: The Ethnography of Communication (pp. 407-434). New York: Holt, Rinehart, and Winston.

De Fina, A. (2007). Code Switching and Construction of Ethnic Identity in a community of Practice. Language in Society, 36, 371-392. http://dx.doi.org/10.1017/S0047404507070182

Eckert, P., \& McConnell-Ginet, S. (1992). Think practically and look locally: language and gender as community-based practice. Annual Review of Anthropology, 21, 461-490. http://dx.doi.org/10.1146/annurev.an.21.100192.002333

Eldridge, J. (1996). Code-Switching in a Turkish Secondary School. ELT Journal, 50(4), 303-311. 
http://dx.doi.org/10.1093/elt/50.4.303

Ferguson, G. (2003). Classroom codeswitching in post-colonial contexts: Functions, attitudes and policies. AILA Review, 16(1), 38-51. http://dx.doi.org/10.1075/aila.16.05fer

Fishman, J. (1972). The sociology of language: An interdisciplinary social science approach to language in society. Massachusetts: Newbury.

Gardner-Chloros, P., \& Katerina, F. (2003). How Code-switching Mediates Politenes: Gender-related Speech Among London Greek-Cypriots. Sociolinguisitc Studies, 4(2). http://dx.doi.org/10.1558/sols.v4i2.505

Gmperz, J. (1982). Dicourse Strategies. Cambridge University Press. http://dx.doi.org/10.1017/CBO9780511611834

Holmes, J. (2013). An introduction to sociolinguistics. New York: Routledge.

Hughes, C., Shaunessy, E., Brice, A., Ratliff, M. A., \& McHatton, P. A. (2006). Code Switching Among Bilingual and Limited English Proficient Students: Possible Indicators of Giftedness. Journal for Education of the Gifted, 30(1), 7-28.

Jegede, O. (2012). Roles of code switching in multilingual public primary schools in Ile-Ife, Nigeria. American Journal of Linguistics, 1(3), 40-46.

Jorgensen, N. (2003). Languging Among Fifth Graders: Codes-switching in Conversation 501 of the Koge Project. Journal of Multilingual and Multicultural Development, 24(1/2), 126-148. http://dx.doi.org/10.1080/01434630308666493

Li, W. (1998). The'why'and'how'questions in the analysis of conversational code-switching. Code-switching in conversation: Language, interaction and identity (pp. 156-179). Routledge: London.

Liang, X. P. (2006). Identity and language functions: High school Chinese immigrant students' code-switching dilemmas in ESL classes. Journal of Identity, Language \& Education, 5(2), 143-167. http://dx.doi.org/10.1207/s15327701jlie0502_3

Lin, A. (2000). Deconstructing "mixed code". Language and education in postcolonial Hong Kong, pp. 179-194.

Mahsain, F. (2015). Motivations behind code-switching among Kuwaiti bilingual schools' students. Diss. University of Manchester.

Milroy, L., \& Muysken, P. (1995). One Speaker, Two Languages: Cross-disciplinary perspectives on Code-switching. Cambridge University Press. http://dx.doi.org/10.1017/cbo9780511620867

Myers-Scotton, C. (1993). Social Motivations for Code Switching: Evidence from Africa. Oxford University Press.

Nilep, C. (2006). Code Switching. Scociocultural Lingisitcs in Colodardo Research in Linguistics, 19, 1-22.

Poplack, S. (1980). Sometimes I'll start a sentence in Spanish Y TERMINO EN ESPAÑOLA: towards a typology of code-switching. Linguistics, 18, 581-618. http://dx.doi.org/10.1515/ling.1980.18.7-8.581

Rampton, B. (1995). Language Crossing and the Problematization of ethnicity and socialization. Pragmatics, 5(4), 485-513. http://dx.doi.org/10.1075/prag.5.4.04ram

Rirard, C. (2010). Behind the Notebook: Following English-Spanish Adolescents Code-switching in Début. The Undergraduate Jounrnal of Languages, Languistics and Area Studies, 1(1), 34-43.

Rosenthal, S., \& Kathlean, M. (2011). Age Prediction in Blogs: A Study of Style, Context and Online Behavior in Pre- and Post-social Media Generations. Proceedings of the $49^{\text {th }}$ Annual Meeting of the Association for Computational Linguistics, pp. 763-772.

Stroud, C. (1998). Perspectives on cultural variability of discourse and some implications for code-switching. Code-switching in conversation: language, interaction and identity (pp. 321-348). Routledge: London.

Woolard, K. (2006). Codeswitching. In A. Duranti (Ed.), A Companion of Linguistic Anthropology (pp. 73-94). Blackwell Publishing.

\section{Notes}

Note 1. Although code switching and code mixing are two different linguistic phenomena, however, they will be used under the generic term code switching in the present study. 
Note 2. Oh my god.

Note 3. What's up.

Note 4. Laugh out loud.

Note 5. Nada Algharabali, whose two sons have attended LFK for the last 13 years.

Note 6. Assuming he means French and/or English.

\section{Appendix A}

\section{Questionnaire Intended for LFK Students}

* Please answer the following questions linked to daily use of these different languages: French, English and Arabic (Fr/ Eng/ Arb, henceforth). Choose only the languages you usually utilize.

1. Gender: Male Female

2. Nationality:

3. Age: $12-14 \quad 14-16 \quad 16-18$

\section{At School}

4. Do you mix between (Fr/ Eng/ Arb) when talking with your friends during recess?

- Yes

- Often

- Sometimes

- Never

5. Do you mix between (Fr/ Eng/ Arb) when talking with your friends at home time (15:00 pm)?

- Yes

- Often

- Sometimes

- Never

\section{At Home}

6. Do you mix between (Fr/ Eng/ Arb) when talking with:

a) Your parents

- Yes

- Often

- Sometimes

- Never

b) Your Sibling(s)

- Yes

- Often

- Sometimes

- Never

c) Your friends

- Yes

- Often

- Sometimes

- Never 


\section{At School}

7. Why do you mix between (Fr/ Eng/ Arb) when talking with your friends during recess? Multiple answers are possible.

- Laziness

- Comfort

- Exchanging secrets

- Peer pressure (Friends' influence)

- Lack of vocabulary

8. Why do you mix between $(\mathrm{Fr} / \mathrm{Eng} / \mathrm{Arb})$ when talking with your friends at home time $(15: 00 \mathrm{pm})$ ?

- Laziness

- Comfort

- Exchanging secrets

- Peer pressure (Friends' influence)

- Lack of vocabulary

\section{At Home}

9. Why do you mix between (Fr/ Eng/ Arb) when communicating with people around you?

- Laziness

- Comfort

- Exchanging secrets

- Peer pressure (Friends' influence)

- Lack of vocabulary

10. In your opinion, what do your teachers think when you mix between

(Fr/ Eng/ Arb) while talking during recess?

- They are not bothered

- They mind to a certain extent

- They prefer us to speak French more often

- They don't like us mixing between languages

- They prefer us to speak French all the time

11. In your opinion, what do your parents think when you mix between

(Fr/ Eng/ Arb) when talking at home?

- They are not bothered

- They mind to a certain extent

- They prefer us to speak French more often

- They don't like us mixing between languages

- They prefer us to speak French all the time

12. In general, how often to you mix between (Fr/ Eng/ Arb)?

- All the time

- Often

- Rarely

- Never

13. Please do not hesitate to comment on the idea of mixing between

(Fr/ Eng/ Arb) when communicating. 


\section{Appendix B}

\section{Questionnaire Intended for LFK Teachers}

* Please answer the following questions linked to the students' daily use of these different languages: French, English and Arabic ( $\mathrm{Fr} / \mathrm{Eng} / \mathrm{Arb}$, henceforth). Choose only the languages they usually utilize.

1. Gender: Male Female

2. Nationality:
3. Age: $20-30$
$30-40$
$40-50$
$50-60$

4. At which age do students mix between ( $\mathrm{Fr} / \mathrm{Eng} / \mathrm{Arb})$ ?

$-12-14$

$-14-16$

$-16-18$

5. Based on your experience as a teacher, who mixes more between

(Fr/ Eng/ Arb)?

- Boys

- Girls

- Both boys and girls

6. Why do you think students mix between ( $\mathrm{Fr} / \mathrm{Eng} / \mathrm{Arb})$ ? Multiple answers are possible.

- Laziness

- Comfort

- Exchanging secrets

- Peer pressure (Friends' influence)

- Lack of vocabulary

7. How often would you prefer your students to utilize French in Class?

- All the time

- Very often

- Often

- Not very often

- Never

8. How often would you prefer your students to utilize French during recess?

- All the time

- Very often

- Often

- Not very often

- Never

9. How often would you prefer your students to utilize French at home time (15:00 pm)?

- All the time

- Very often

- Often

- Not very often

- Never

10. In general, how often do you think students mix between (Fr/ Eng/ Arb)?

- All the time

- Very often 
- Often

- Not very often

- Never

11. Please do not hesitate to comment on the idea of students mixing between ( $\mathrm{Fr} / \mathrm{Eng} / \mathrm{Arb}$ ) when communicating.

Thank you :)

\section{Appendix C}

Transcription

- Round brackets: indicates gender

- Square brackets: para-linguistics (e.g., pauses or gestures)

- Italic font: Arabic

- Bold font: English

- Underlined text: French

- [Y] voiced pharyngeal approximant

- $\quad[\hbar] \quad$ voiceless pharyngeal fricative

\section{Copyrights}

Copyright for this article is retained by the author(s), with first publication rights granted to the journal.

This is an open-access article distributed under the terms and conditions of the Creative Commons Attribution license (http://creativecommons.org/licenses/by/3.0/). 